\title{
Third Generation Personal Communication Systems: A Study of Case on the Implementation of UTRA WCDMA FDD Networks
}

\author{
Roger Pierre Fabris Hoefel and Sílvio César Dutra
}

\begin{abstract}
It is developed a study of case, unifying theoretical and practical aspects, regarding the cell-planning of a third generation $(3 \mathrm{G})$ network that implements a radio interface based on the Universal Mobile Telecommunications System (UMTS) Terrestrial Radio Access (UTRA) Wideband Code division Multiplexing (WCDMA) Frequency Division Duplexing (FDD) technology. The used methodology is validated by the close agreement between the measured and estimated cell coverage.
\end{abstract}

Keywords: UTRA,WCDMA, link budget, coverage, teletraffic.

\section{INTRODUCTION}

In Brazil, 3G networks were implemented in 427 cities (58.2\% of the Brazil's population) until the end of 2008. However, the number of $3 \mathrm{G}$ devices was just 2.2 million (i.e. the penetration rate of $3 \mathrm{G}$ services in these cities was only of $2.0 \%$ ). Besides this, more than $80 \%$ of Brazilian mobile subscribers have used pre-paid services. Therefore, the operators must implement a roll-strategy that aims at optimizing aggressively the capital expenditure/ operational expenditure (CAPEX/OPEX). Basically, the 3G systems are being implemented in target markets of major metropolitan areas in overlay with $2 \mathrm{G}$ Global System for Mobile (GSM) networks.

Although we have recognized that there is lot of knowledge in the developed world, we strongly believe that there is still a wide room for contributions that take into account practical aspects regarding the developing of 3G UTRA networks in developing countries like Brazil. This represents a unique opportunity for academic researchers to establish partnerships with the telecom operators to get a synergy between theoretical and practical issues regarding the deployment of advanced wireless networks.

In order to accomplish our goals this paper is organized as follows. Section II defines two different environments (urban and dense urban clutters) analyzed in this contribution. Section III briefly describes the topology used in the implementation of Nodes $B$ (which is the terminology that describes a base station, BS, in UTRA technology). Section IV first analyzes the traffic profile in macrocell located in urban and dense urban clutters, where these results are used to determine the load factor necessary to plan the system. Section V describes the methodology used for the UTRA network (UTRAN) planning. Section VI and VII presents the uplink and downlink link budget (LB), respectively. The estimation of the cell coverage is carried out at Section VIII. The final remarks are drawn in Section IX.

\section{II - URBAN AND SUBURbAN ENVIRONMENTS}

The clutter classes define the distinct morphological structures of the communication environment [1, p 230]. In this contribution, we shall analyze two typical clutters used in the real-world UTRAN planning process:

Manuscript received on April, 02, 2009. Revised on July, 29, 2009.

Roger Pierre Fabris Hoefel is with Department of Electrical Engineering, Federal University of Rio Grande do Sul (UFRGS), Porto Alegre, Rio Grande do Sul (RS), Brazil; E-mail: roger.hoefel@ufrgs.br.

Eng. Sílvio César Dutra is with VIVO, Porto Alegre, RS, Brazil.
1. Urban (Fig. 1a): In these environments the density of the constructions is considerably higher than in suburban areas. Small vegetation is present and the average building height is no bigger than $40 \mathrm{~m}$. The main streets are easily visualized.

2. Dense Urban (Fig. 1b): It is dense populated and constructed area with narrow streets. It can be downtown areas as well.

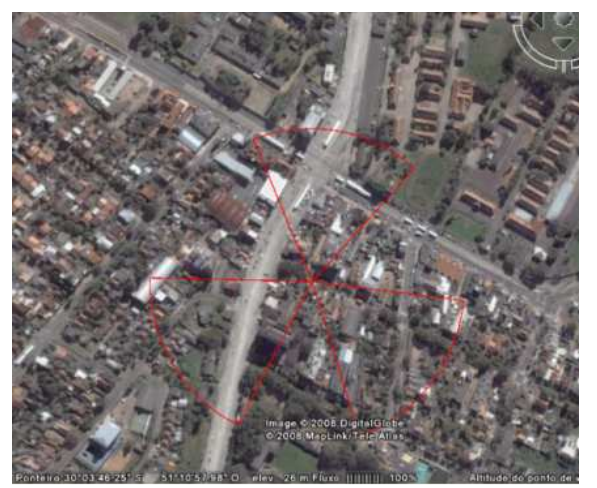

Fig. 1a-Urban clutter.

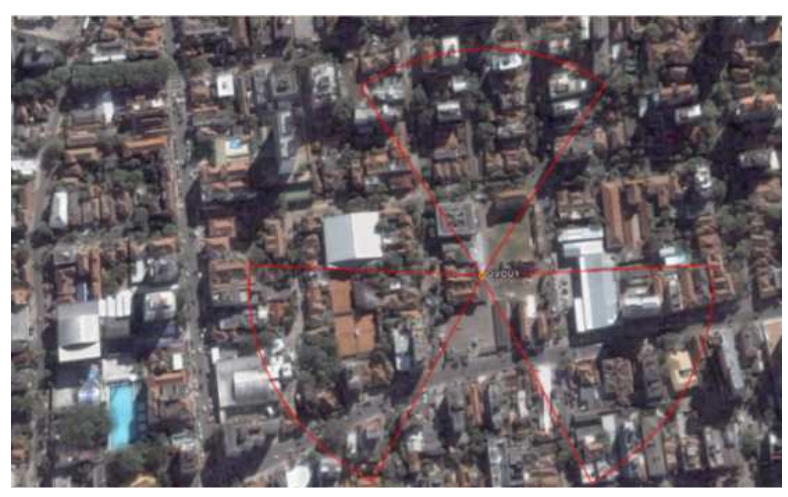

Fig. 1b-Dense urban clutter.

Fig. 1 - Urban and dense urban clutters in Porto Alegre, Brazil.

\section{III - NODE B TOPOLOGY}

Fig. 2 depicts a simplified block diagram of the Node $B$ and radio network controller (RNC) used in our three-sectorized cells. Each sector uses a panel antenna model BX-6516DS-VTM, manufactured by the company Andrew (see Fig. 3). The remote radio unit (RRU) is located near the antenna and, therefore, we can neglect the cable loss in the LB analysis (see sections VI and VII). The left-side of Fig. 4 shows the RRU. The band base unit (BBU) performs layer 1 (L1) processing (e.g. scrambling, coding, interleaving, modulation). The BBU and the DC box (responsible for providing power supply to the system) are shown in the rightside of Fig. 4. The radio network controller (RNC) is responsible for the control of UTRAN radio resources. Basically, it performs L2 processing (e.g. radio resource management, RRM, algorithms such as soft and softer handover, outer loop power control, call admission control). Finally, we emphasize that this topology is a true three-sectorized system since each sector uses its own power amplifier [2, p. 201]. 


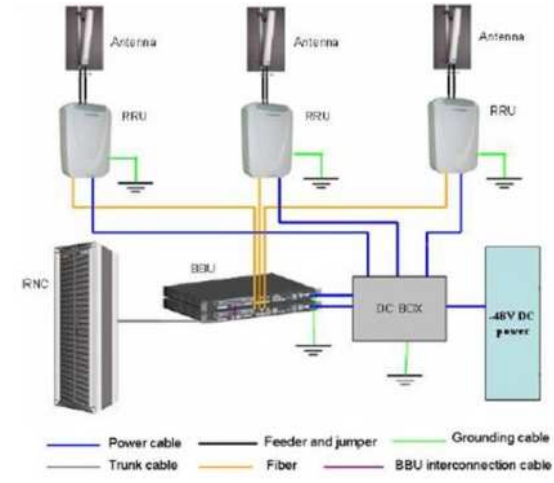

Fig. 2 - Simplified topology of Node B and RNC.
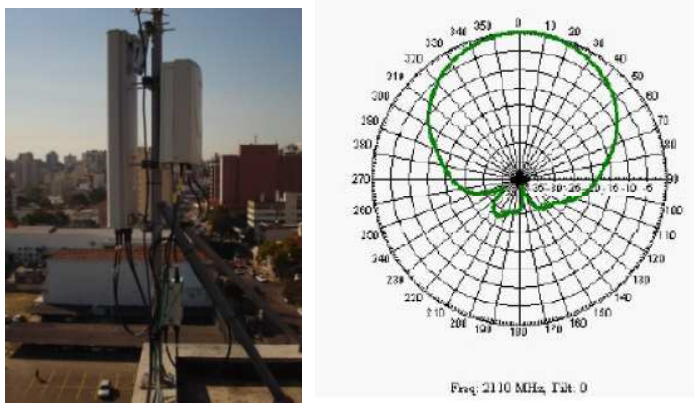

Fig. 3 - Panel Antenna BX-6516DS-VTM.
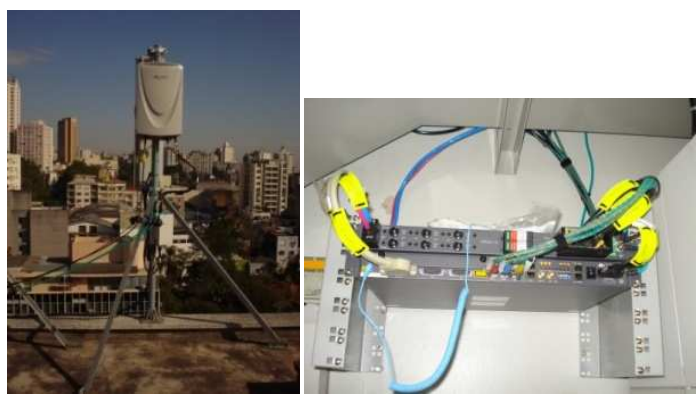

Fig. 4 - RRU (left-side); BBU and DC box (right-side).

\section{IV - TELETRAFFIC ANALYSIS}

In the initial deployment stage of WCDMA networks it is fundamental to optimize aggressively the CAPEX/OPEX due to low basis of subscribers. Therefore, the macro cells (environments where the antennas of Nodes $B$ are mounted above the roof-top level, as shown in Figs. 3 and 4) are designed to be coverage limited instead of interference (capacity) limited. In the middle term run there is an increase of the ARPU (average revenue per user) due large basis of subscribers that use advanced multimedia services, and, therefore, the Nodes $B$ can be easily adapted to cap with an interference limited environment.

In coverage limited systems the range is limited by the uplink since the interference at the Node $B$ can be controlled by setting a convenient value to the noise rise (NR) parameter. In this case, it is the user equipment (UE) effective radiate power (EIRP) that limits the cell range since the cell load is controlled by the NR.

The NR is defined as the additional power that must be delivered by a UE to overcome the interference generated by other UEs. Mathematically, the NR is the ratio of total interference $I_{\text {total }}$ to noise power $P_{n}$ :

$$
N R=\frac{I_{\text {intra }}+I_{\text {inter }}+P_{n}}{P_{n}}=\frac{I_{\text {total }}+P_{n}}{P_{n}},
$$

where $I_{\text {intra }}$ and $I_{\text {inter }}$ denote the intracell and intercell interference, respectively.
The NR can also be written as [2, p. 192]

$$
N R=\frac{1}{1-\eta_{u l}} \text {. }
$$

where the uplink load factor is defined as the sum of the fractional loads of all $N_{U L}$ mobile stations (MSs) in the system:

$$
\eta_{u l}=\frac{I_{\text {intra }}+I_{\text {inter }}}{I_{\text {total }}}=(1+f) \sum_{i=1}^{N_{U L}} \frac{P_{i}}{I_{\text {total }}}=\frac{E_{b} / N_{o}}{W / R} \cdot N_{u l} \cdot v \cdot(1+f) .
$$

We have used the following definitions in (3): $P_{i}$ is the received power from ith user; $E_{b}$ is energy per bit; $N_{o}$ is the oneside noise spectral density; $W$ is the WCDMA chip rate $(3.84$ $M c p s) ; R$ is the user bit rate in bps; $N_{u l}$ is the number of UEs in the uplink; $v$ is the UE activity factor.

The other cell interference factor is defined as

$$
f=\frac{I_{\text {inter }}}{I_{\text {intra }}}
$$

where its average value depends on the propagation environment (path loss exponent $\gamma$, shadowing standard deviation $\sigma_{d B}$ ), cell topology, antenna system and so forth. Assuming $\gamma=4$ and $\sigma_{d B}=8$, then we have $f=0.60$ [3] and $f=0.65$ [2, p. 193] for macro cells with one and three sectors, respectively.

Assuming a uniform load in the system, the downlink load factor is defined as

$$
\eta_{d l}=\frac{E_{b} / N_{o}}{W / R} \cdot N_{d l} \cdot v \cdot[(1-\alpha)+f],
$$

where $\alpha$ is the average orthogonality factor in the cell. For ITU vehicular A channel $\alpha=0.5$, and $\alpha=0.1$ for ITU pedestrian A channel [2, p, 194].

The dimensioning, planning and implementation of the UTRA FDD network under analysis uses the infrastructure (e.g. cell sites, core network) of an operational GSM network. Therefore, in this section we shall estimate the number of WCDMA channels based on traffic measures done in a three-sectorized GSM cell.

Fig. 5 shows the voice traffic per sector in Erlangs (Erl) measured in urban (Fig. 5a) and dense urban (Fig. 5b) cells. These measurements were carried out in Porto Alegre, Brazil, in late 2008. We can observe a traffic diminishing on the weekends and a cyclostationary behavior of the traffic load. In this contribution, the system planning is carried out considering the busy hour, where the peak load is served with a specified quality-of-service (QoS) based on the signal-to-interference-plus-noise ratio (SINR) and resource availability (quantified by its blocking probability). Based on Fig. 5, we must consider a traffic load in the busy hour of 8 and $16 \mathrm{Erl}$ in urban and dense urban cells, respectively.

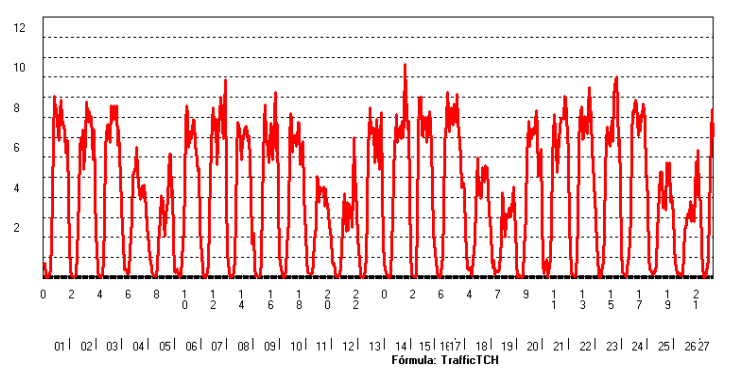

Fig. 5a - Voice traffic per sector in Erlangs versus acquisition date: urban cell.

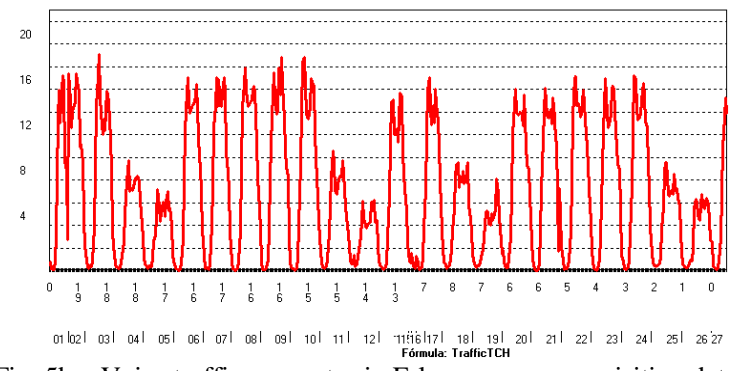

Fig. $5 b$ - Voice traffic per sector in Errangs versus acquisition date: dense urban cell. 
The Erlang capacity is calculated using the Erlang B formula [4, p.105] when the capacity is hard blocked (i.e. limited by the amount of hardware as in GSM systems). The Erlang B formula is based on an $M / M / m / m$ queue, where the arrival and departure events are modelled by a birth and death Poisson process (i.e. the time between arrivals $(M)$ and the time between departures $(M)$ follow an exponential negative probability density function) and the number of servers $(m)$ is equal to maximum number of subscribers served by the system $(m)$. Using an Erlang B table [5, $\mathrm{p}, 273]$, then it is easily verified that it is necessary 8 channels for the urban cell $(8 \mathrm{Erl})$ and 25 channels for the dense urban cell (16 $E r l)$ in a hard blocked system with a blocking probability of $1 \%$.

In WCDMA systems the capacity is not hard blocked since it is possible to support an increase of interference in detriment of a controllable decreasing of QoS or coverage (i.e. there is a trade between capacity and coverage and vice versa). So, we can use the soft capacity concept to estimate the Erlang capacity [2, p. 204].

The soft capacity methodology takes into account that the total channel pool statistically available (interference pool) can be estimated by multiplying the number of channels per sector in the equally loaded case by the total normalized interference $(1+f)$. The algorithm to estimate the soft capacity is described in the following:

1. Set a target value for the uplink load factor. It is used the uplink since the system is coverage limited.

2. Calculate the number of channels $N_{u l}$ per sector using (3).

3. Determine the total channel pool as

$N_{\text {poll }}=N_{u l}(1+f)$.

4. Given a blocking probability $p_{\text {blocking, }}$ calculate the maximum offered traffic $\left(E_{\text {poll }}\right)$ using the Erlang B model

5. The Erlang capacity $(E)$ per sector is obtained by dividing the maximum offered traffic by the total normalized interference (see 7) in order to consider the average traffic in the target sector.

$E_{\text {soft_capacity }}=\frac{E_{\text {poll }}}{1+f}$.

Earlier adapters have used $3 \mathrm{G}$ systems for multimedia applications, while for the vast majority of cost sensitive subscribers video call is a serious motivation to migrate to $3 \mathrm{G}$ systems. Hence, we shall analyze the Erlang capacity for $12.2 \mathrm{kbps}$ adaptive multirate (AMR) speech service (bit error rate, BER, of $10^{-3}$ ) and $64 \mathrm{kbps}$ circuit-switched (CS) video conversation (BER of $10^{-4}$ ), as shown in Tab I. The values of SINR per bit are the practical ones used by the telecom operator VIVO in the process of planning and optimization its operational network.

\section{TABLE I}

Parameters used to estimate the Erlang capacity: $\mathrm{W}=3.84 \mathrm{Mcps} ; \mathrm{f}=0.65 ; \alpha=0.5$.

\begin{tabular}{|c|c|c|}
\hline Parameter & Speech & Video call \\
\hline $\mathrm{R}$ & $12.2 \mathrm{kbps}$ & $64 \mathrm{kbps}$ \\
\hline Activity & 0.67 & 1.0 \\
\hline $\mathrm{E}_{\mathrm{b}} / \mathrm{I}_{0}$ & $7.0 \mathrm{~dB}$ & $7.5 \mathrm{~dB}$ \\
\hline
\end{tabular}

Fig. 6 shows the uplink (downlink) Erlang capacity as a function of the uplink (downlink) load factor. It is assumed a $p_{\text {blocling }}$ of $1 \%$ and it is used the data shown in Tab. I. We can see clearly that the uplink limits the capacity in a coverage limited system. We shall see in next section that the system capacity in an interference (capacity) limited system is constrained by the downlink due to power limitation of the Node B transmitter. We observe that the processing gain $\left(\mathrm{G}_{\mathrm{p}}\right)$ for $64.0 \mathrm{kbps}$ CS video is $\sim 5$ lesser than the one obtained for $12.2 \mathrm{kbps}$ AMR speech. Therefore, this explains the decrease of approximately five in the number of channels when the system is uniformly loaded with video calls. This coupled with the poll effect of the number of channels in the Poisson birth-death process of Erlang B model causes a stupendous decrease in the Erlang capacity for video calls.

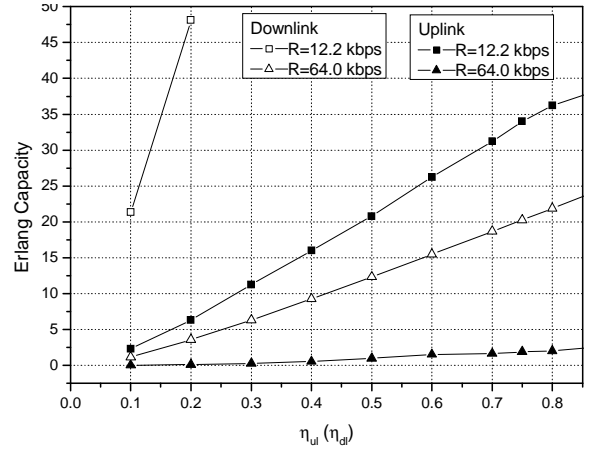

Fig. 6 - Erlang soft capacity vs uplink (downlink) load factor.

Comparing the results of Figs. 5 and 6 and assuming speech service, we can easily verify that the urban $(8 \mathrm{Erl})$ and dense urban (16 Erl) cells can be designed to operate with a uplink load factor of 0.25 an 0.40 in order to implement a coverage limited system. Finally, notice that when the uplink load factor $\eta_{u l}$ approaches 1 , then the corresponding NR tends to infinity (see 2) and the system has reached its pole capacity. In real world, RRM algorithms act to limit the load factor to 0.75 (6.0 dB of noise raise) in capacity limited system to avoid system instability.

In this contribution, based on measurement of real traffic, we have assumed voice traffic to estimate the Erlang capacity. As reference for further works we observe that the planning for multiservice in hard capacity system can be carried out using the multidimensional Erlang B formula [6]. An analytical approach applied to WCDMA networks can be found in [7].

\section{V - UTRAN PLANNING}

Basically, the first order planning of UTRAN takes into account the following aspects [1, p.239]:

1. Uplink cell load estimation: for coverage limited systems is assumed a maximum NR of $3 \mathrm{~dB}$ (see 1).

2. Uplink link budget (LB) calculation: the LB is a table sheet of gains and losses between transmitter and receiver used to determine the maximum allowable path loss (see section VI).

3. Downlink power allocation: the downlink power allocation is carried out taking into account the uplink cell load (see section VII).

4. Downlink LB calculation: the maximum allowable path loss is estimated. The system is planned such as that the maximum downlink path loss is not less than the one obtained for the uplink (see section VII).

5. Cell coverage estimation: the cell range is estimated using empirical propagation models (e.g. COST-231 Hata; COST-231 Walfish-Ikegami, Manhattan model) and the maximum allowable path loss (see section VIII).

6. Cell capacity estimation: the uplink and downlink capacity are calculated using the uplink and downlink load factors, respectively, used in the LB analyzes. Other factors, such as QoS, distribution of users, traffic profile can be also taken into account.

Hereafter, the LB analysis shall be done assuming the following specific European Telecommunications Standardization Institute (ETSI) environments: (1) outdoor to indoor and pedestrian $3 \mathrm{~km} / \mathrm{h}$ for dense urban macrocells; (2) outdoor to indoor $50 \mathrm{~km} / \mathrm{h}$ vehicular in urban macrocells. These real network scenarios have a strong influence in the choice of link budget parameters, as we will see in the next two sections.

\section{VI - UPLINK LINK BUDGET}

In UTRAN, the LB is mainly used for: (i) to balance between the uplink and downlink since the uplink is coverage limited due to UE power limitation and the downlink is capacity limited because the Node B power must be shared among all users in the cell (i.e. if the load increases then the power available per user decreases); (ii) to estimate the cell range; (iii) to estimate the coverage thresholds. 
Tab. II shows a LB for the uplink UTRA WCDMA network.

TABLE II

Uplink link budged for a WCDMA network.

\begin{tabular}{|c|c|c|c|}
\hline Line & Symbol & Description & Formula \\
\hline \multicolumn{4}{|c|}{ UE Transmitter } \\
\hline 1 & $\mathrm{P}_{\mathrm{tx}}$ & Transmitter Power $(\mathrm{dBm})$ & $24 \mathrm{dBm}$ \\
\hline 2 & $\mathrm{G}_{\mathrm{tx}}$ & Transmitter Antenna Gain $(\mathrm{dBi})$ & $O d B i$ \\
\hline 3 & EIRP & Transmitter EIRP $(\mathrm{dBm})$ & Eq. (8) \\
\hline \multicolumn{4}{|c|}{ Node B Receiver } \\
\hline 4 & $\mathrm{G}_{\text {diver }}$ & Antenna Rx Diversity Gain $(d B)$ & $3 d B$ \\
\hline 5 & $\mathrm{G}_{\mathrm{rx}}$ & Receiver Antenna Gain $(d B i)$ & $17 \mathrm{dBi}$ \\
\hline 6 & $\mathrm{~L}_{\text {cable }}$ & Cable Loss $(d B)$ & $O d B$ \\
\hline 7 & $\mathrm{~N}_{\mathrm{o}}$ & Noise Spectral Density $(\mathrm{dBm} / \mathrm{Hz})$ & $-174 \mathrm{dBm} / \mathrm{Hz}$ \\
\hline 8 & $\mathrm{~F}$ & Noise Figure $(d B)$ & $5 d B$ \\
\hline 9 & W & System Bandwidth $(\mathrm{dB}-\mathrm{Hz})$ & $65.84 \mathrm{~dB}-\mathrm{Hz}$ \\
\hline 10 & $\mathbf{N}$ & Noise Power $(\mathrm{dBm})$ & Eq. (10) \\
\hline 11 & $\mathrm{R}_{\mathrm{b}}$ & Data Rate $(d B-b p s)$ & 40.86 dB-bps \\
\hline 12 & $\mathrm{E}_{\mathrm{b}} / \mathrm{I}_{0}$ & SINR per bit $(d B)$ & $7.0 \mathrm{~dB}$ \\
\hline 13 & $\mathbf{S}_{\mathrm{rx}}$ & Receiver Sensitivity $(\mathrm{dBm})$ & Eq. (11) \\
\hline \multicolumn{4}{|c|}{ Margins } \\
\hline 14 & $\eta_{\mathrm{ul}}$ & Uplink Noise Rise (dB) & $4.0 \mathrm{~dB}$ \\
\hline 15 & $\mathrm{M}_{\mathrm{sh}}$ & Soft Handover $(d B)$ & $O d B$ \\
\hline 16 & $\mathrm{M}_{\mathrm{pc}}$ & Power Control Headroom $(d B)$ & $2 d B$ \\
\hline 17 & $\mathrm{M}_{\mathrm{tx}}$ & Transmit Power Rise $(d B)$ & $1 d B$ \\
\hline 18 & $\mathrm{M}_{\mathrm{b}}$ & Body Loss $(d B)$ & $1 d B$ \\
\hline 19 & $\mathbf{M}$ & Total Margin $(d B)$ & Eq. (12) \\
\hline 20 & $\mathbf{L}_{\mathbf{p}}$ & Maximum Path Loss (dB) & Eq. (13) \\
\hline \multicolumn{4}{|c|}{ Outdoor Coverage Reliability } \\
\hline 21 & $\sigma_{d B}$ & \begin{tabular}{lcc|c} 
Outdoor & Shadowing & Standard & \\
Deviation $(\mathrm{dB})$ & & &
\end{tabular} & $\begin{array}{r}7 d B \text { or } \\
8 d B \text { (urban) }\end{array}$ \\
\hline 22 & $X_{\sigma}$ & Outdoor Slow Fading Margin (dB) & Eq. (14) \\
\hline 23 & $\mathbf{L}_{\mathbf{p}, \text { outdoor }}$ & Maximum Outdoor Path Loss & Eq. (15) \\
\hline \multicolumn{4}{|c|}{ Indoor Coverage Reliability } \\
\hline 24 & $\mathrm{M}_{\text {indoor }}$ & Indoor Penetration Loss $(\mathrm{dB})$ & $20 d B$ \\
\hline 25 & $\sigma_{d B, \text { indoor }}$ & $\begin{array}{lll}\text { Indoor } & \text { Shadowing } & \text { Standard } \\
\text { Deviation }(\mathrm{dB}) & \end{array}$ & $5 \mathrm{~dB}$ \\
\hline 26 & $\sigma_{d B, t o t a l}$ & $\begin{array}{r}\text { Combined Shadowing } \\
\text { Standard Deviation (dB) }\end{array}$ & Eq. (16) \\
\hline 27 & $Y_{\sigma}$ & Indoor Slow Fading Margin (dB) & Eq. (17) \\
\hline 28 & $\mathbf{L}_{\mathrm{p} \text {,indoor }}$ & Maximum Outdoor Path Loss & Eq. (18) \\
\hline
\end{tabular}

1. It is assumed a Class $3 \mathrm{UE}: 24 \mathrm{dBm}(250 \mathrm{~mW})$.

2. It is assumed an ommidirectional antenna with gain of $0 \mathrm{dBi}$.

3. The effective isotropic transmitter power (EIRP) is given by $E I R P=P_{t x}+G_{t x}$

4. It is used two receiver antennas with a maximum ration combining (MRC) receiver, i.e. antenna diversity gain of $3 \mathrm{~dB}$.

5. The receiver antenna has an average gain of $17 d B i$ (see Fig. 7).

6. The cable loss is $0 \mathrm{~dB}$ since RRU is located near the antenna (see Fig. 3).
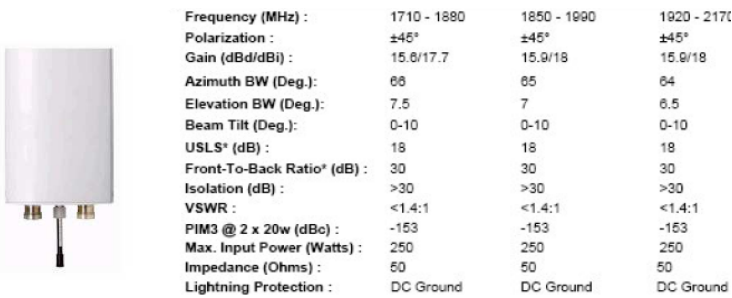

Fig. 7 - Data sheet of a panel antenna BX-6516DS-VTM.
7. The one side noise spectral density $N_{0}$ models the additive white Gaussian noise (AWGN) at the receiver input:

$N_{0}=k \cdot T_{0}$,

where the Boltzaman constant $k$ is equals to $-198.60 \mathrm{dBm} / \mathrm{K}$ $\mathrm{Hz}$ and $T_{o}$ is the effective noise temperature in degrees Kelvin (k). Assuming, $T_{0}=270{ }^{0} K(24.31 d B-K)$, then $N_{o}=-174$ $\mathrm{dBm} / \mathrm{Hz}$.

8. The noise figure $F$ is defined by the ratio of the SINR at the input of a network to the SINR at the output at the network. It measures the noise introduced by the analogical front-end at the receiver. It is assumed a typical value of $5 d B$.

9. The bandwidth is equal to the chip rate $3.84 \mathrm{Mcps}$ (65.84 $\mathrm{dB}$ $\mathrm{Hz}$ ).

10. The noise power in $\mathrm{dBm}$ is given by

$$
N=N_{0}+F+W \text {. }
$$

11. It is assumed an AMR speech service $(12.2 \mathrm{kbps}=40.86 \mathrm{~dB}$ bps).

12. The target SINR per bit is of $7.0 \mathrm{~dB}$.

13. The receiver sensitivity level in $\mathrm{dBm}$ is given by

$$
S_{r x}=\frac{E_{b}}{N_{0}}+N+R_{b}-W .
$$

14. It is assumed a coverage limited with an uplink factor of 0.4 (see section III). So, the interference margin is of $4.0 \mathrm{~dB}$

15. Simulation results for soft handover gain give almost positive gains (e.g. for the uplink and downlink, the gain is around 2.0 $d B$, when the path loss from UE to two different Nodes B is equal). However, measurements with real equipment show an average gain of $0.5 \mathrm{~dB}$ when power control commands are combined and, surprisingly, loss of around of $1.9 \mathrm{~dB}$ have been measured when power commands are not combined [1, p. 234], [9]. In this contribution, we shall adopt a neutral approach considering a net gain of $0.0 \mathrm{~dB}$.

16. The power control headroom margin (fast power control margin) takes into account that slow mobile UEs located at cell edge must transmit at maximum power to mitigate the multipath fading.

17. The transmit power rise is a necessary margin due to power spikes.

18. The body loss occurs when the user holds the UE in the hand and close to the head.

19. The margins of the system in $\mathrm{dB}$ can be grouped as

$$
M=\eta_{u l}+M_{s h}+M_{p c}+M_{t x}+M_{b}
$$

20. The maximum allowed path loss in $\mathrm{dB}$ is given by

$$
L_{p}=\left(E I R P+G_{\text {diver }}+G_{r x}-L_{\text {cable }}\right)-S_{r x}-M \text {. }
$$

21. The slow fading shadowing is modeled by a log-normal random variable with zero mean and standard deviation $\sigma_{d B}$ of 7 (dense urban) and $8 d B$ (urban clutter). The standard deviation is lesser in the dense urban clutter due to the greater environment homogeneity regarding to the urban clutter.

22 . The coverage probability $p_{\text {cov,edge }}$ quantifies the likelihood that the target signal at cell edge is greater than a required signal threshold $P_{t h r}$. It is given by

$$
p_{\text {out }, \text { edge }}=Q\left(\frac{P_{t h r}-P_{r x}}{\sigma_{d B}}\right)=Q\left(\frac{X_{\sigma}}{\sigma_{d B}}\right) \text {. }
$$

Urban clutter: $p_{\text {cov,edge }}=90 \%, \sigma_{d B}=8.0 \mathrm{~dB}$, then $X_{\sigma}=10.3 \mathrm{~dB}$.

Dense urban clutter: $p_{\text {cov,edge }}=90 \%, \sigma_{d B}=7.0 \mathrm{~dB}$, then $X_{\sigma}=9.0 \mathrm{~dB}$

23. The maximum outdoor path loss in $\mathrm{dB}$ is given by

$$
L_{p, \text { outdoor }}=L_{p}-X_{\sigma} \text {. }
$$

24. The indoor penetration loss is added to the path loss of an outdoor user, with a UE height of $1.5-2 \mathrm{~m}$. Typical penetration loss in urban clutters are between $16-20 \mathrm{~dB}$, with a standard deviation of $4 \mathrm{~dB}$. In dense clutters these values are even higher: penetration 
loss between 20-30 $d B$ with a standard deviation of $8 d B$. For cars, the penetration loss is 5-8 dB with a standard deviation of $2 d B$. Here, we have assumed $20 \mathrm{~dB}$ for both clutters.

25. It is assumed $5.0 \mathrm{~dB}$ for the indoor shadowing standard deviation $\sigma_{d B \text {,indoor }}[1]$.

25. The combined standard deviation is given by

$$
\sigma_{d B, \text { total }}=\sqrt{\sigma_{d B}^{2}+\sigma_{d B, \text { indoor }}^{2}},
$$

26. The outage probability $p_{c o v, \text { indoor }}$ is defined by

$$
p_{\text {out }, \text { indoor }}=Q\left(\frac{P_{t h r}-P_{r x}}{\sigma_{d B, \text { total }}}\right)=Q\left(\frac{Y_{\sigma}}{\sigma_{d B, \text { total }}}\right) \text {. }
$$

For dense urban clutter: $p_{\text {cov, indoor }}=90 \%, \sigma_{d B}=7 d B, \sigma_{d B \text {,indoor }}=5$ $d B$, then $\sigma_{d B \text {,total }}=8.6 d B$ and $Y_{\sigma}=11.06 \mathrm{~dB}$.

For dense urban clutter: $p_{\text {cov,indoor }}=90 \%, \sigma_{d B}=8 d B, \sigma_{d B \text {,indoor }}=5$ $d B$, then $\sigma_{d B \text {,total }}=9.43 d B$ and $Y_{\sigma}=12.12 d B$.

23. The maximum indoor path loss in $\mathrm{dB}$ is given by

$$
L_{p, o u t d o o r}=L_{p}-Y_{\sigma}-M_{\text {indoor }} \text {. }
$$

We shall use the link budget data to estimate the cell coverage in Section VIII

\section{VII - DOWNLINK LINK BUDGET}

Tab. III shows the LB for the downlink of an UTRA WCDAM FDD network. It is only detailed the items that change in relation to the uplink LB.

1. The Node B has an output power of $40 \mathrm{~W}$.

2. The power allocated to the common control channels $(\mathrm{CCCH})$ is of $9.62 \mathrm{~W}$. The references [1, p.225] and [10] present interesting aspects on power allocation methodology.

3. The available power to the traffic channels in $\mathrm{dBm}$ is given by

$$
P_{\text {traf }}=10 \log \left(10^{\frac{P_{b s}}{10}}-10^{\frac{P_{c t r l}}{10}}\right) \text {. }
$$

4. It has been assumed 12.2 kbps AMR symmetric speech service. The number of UE in the system is given by

$\mathrm{N}=\left\lfloor\min \left(\mathrm{N}_{\mathrm{ul}}, \mathrm{N}_{\mathrm{dl}}\right\rfloor\right.$,

where, from Eq. (3) the number of UE in the uplink is given by

$$
\mathrm{N}_{\mathrm{ul}}=\frac{\mathrm{W} / \mathrm{R}}{\mathrm{E}_{\mathrm{b}} / \mathrm{N}_{\mathrm{o}}} \cdot \eta_{\mathrm{ul}} \cdot \frac{1}{\mathrm{v} \cdot[1+\mathrm{f}]} \text {. }
$$

Correspondingly, from Eq. (7) the number of UE in the downlink is given by

$$
\mathrm{N}_{\mathrm{dl}}=\frac{\mathrm{W} / \mathrm{R}}{\mathrm{E}_{\mathrm{b}} / \mathrm{N}_{\mathrm{o}}} \cdot \eta_{\mathrm{dl}} \cdot \frac{1}{\mathrm{v} \cdot[(1-\alpha)+\mathrm{f}]} \text {. }
$$

Using the data earlier specified, then $N_{u l}=22.96 N_{d l}=32.94$. Hence, $N=N_{u l}=22$ users.

5 . The allocated power per user in $\mathrm{dBm}$ is given by

$$
P_{\text {user }}=P_{\text {traf }}-10 \log N \text {. }
$$

\section{VIII - COVERAGE ANALYSIS}

We shall use the Okmura-Hata propagation model for a first order estimation of the cell range [11]. Hence, the path loss $L(d B)$ given in $\mathrm{dB}$ is modeled as

$$
\begin{aligned}
L(d B)= & {\left[46.3+33.9 \log f_{c}-13.82 \log h_{b}-a\left(h_{m}\right)\right]+} \\
& {\left[44.9-6.55 \log h_{b}\right] \cdot \log d-L_{c} }
\end{aligned}
$$

where we have used the following definitions: $f_{c}$ is the frequency

\begin{tabular}{|c|c|c|c|}
\hline Line & Symbol & Description & Formula \\
\hline \multicolumn{4}{|c|}{ Node B Transmitter } \\
\hline 1 & $\mathrm{P}_{\mathrm{bs}}$ & Total Transmitter Power $(\mathrm{dBm})$ & $46.0 \mathrm{dBm}$ \\
\hline 2 & $\mathrm{P}_{\text {ctrl }}$ & Control Channels Power $(\mathrm{dBm})$ & $39.83 \mathrm{dBm}$ \\
\hline 3 & $\mathbf{P}_{\text {,traf }}$ & Traffic Channels Power $(\mathrm{dBm})$ & Eq. 19 \\
\hline 4 & $\mathbf{N}$ & Number of users (dB-user) & Eq. 20 \\
\hline 5 & $\mathbf{P}_{\text {user }}$ & Power allocated per user $(\mathrm{dBm})$ & Eq. 23 \\
\hline 6 & $\mathrm{~L}_{\text {cable }}$ & Cable Loss $(d B)$ & $0 \mathrm{~dB}$ \\
\hline 7 & $\mathrm{G}_{\mathrm{tx}}$ & Transmitter Antenna Gain $(\mathrm{dBi})$ & $17 \mathrm{dBi}$ \\
\hline 8 & EIRP & Transmitter EIRP $(\mathrm{dBm})$ & $\# 5$ - \#6 + \#7 \\
\hline \multicolumn{4}{|c|}{ UE Receiver } \\
\hline 9 & $\mathrm{G}_{\text {diver }}$ & Antenna Rx Diversity Gain $(d B)$ & $O d B$ \\
\hline 10 & $\mathrm{G}_{\mathrm{rx}}$ & Receiver Antenna Gain $(d B i)$ & $O d B i$ \\
\hline 11 & $\mathrm{~N}_{\mathrm{o}}$ & Noise Spectral Density $(\mathrm{dBm} / \mathrm{Hz})$ & $-174 \mathrm{dBm} / \mathrm{Hz}$ \\
\hline 12 & $\mathrm{~F}$ & Noise Figure $(d B)$ & $7 \mathrm{~dB}$ \\
\hline 13 & W & System Bandwidth $(\mathrm{dB}-\mathrm{Hz})$ & $65.84 \mathrm{~dB}-\mathrm{Hz}$ \\
\hline 14 & $\mathbf{N}$ & Noise Power $(d B m)$ & $\# 10+\# 11+\# 12$ \\
\hline 15 & $\mathrm{R}_{\mathrm{b}}$ & Data Rate $(d B-b i t / s)$ & 40.86 dB-bps \\
\hline 16 & $\mathrm{E}_{\mathrm{b}} / \mathrm{I}_{0}$ & SINR per bit $(d B)$ & $7.0 \mathrm{~dB}$ \\
\hline 17 & $\mathbf{S}_{\mathrm{rx}}$ & Receiver Sensitivity $(\mathrm{dBm})$ & Eq. (11) \\
\hline \multicolumn{4}{|c|}{ Margins } \\
\hline 18 & $\eta_{\mathrm{ul}}$ & Uplink Noise Rise (dB) & $4 \mathrm{~dB}$ \\
\hline 19 & $\mathrm{M}_{\mathrm{sh}}$ & Soft Handover $(d B)$ & $O d B$ \\
\hline 20 & $\mathrm{M}_{\mathrm{pc}}$ & Power Control Headroom $(d B)$ & $O d B$ \\
\hline 21 & $\mathrm{M}_{\mathrm{tx}}$ & Transmit Power Rise $(d B)$ & $O d B$ \\
\hline 22 & $\mathrm{M}_{\mathrm{b}}$ & Body Loss $(d B)$ & $1 d B$ \\
\hline 23 & $\mathbf{M}$ & Total Margin $(d B)$ & Eq. 12 \\
\hline 24 & $\mathbf{L}_{\mathbf{p}}$ & Maximum Path Loss (dB) & Eq. 13 \\
\hline \multicolumn{4}{|c|}{ Outdoor Coverage Reliability } \\
\hline 25 & $\sigma_{d B}$ & $\begin{array}{llr}\text { Outdoor } & \text { Shadowing } & \text { Standard } \\
\text { Deviation }(\mathrm{dB}) & \\
\end{array}$ & $\begin{array}{r}7 d B \text { or } \\
8 d B \text { (urban) } \\
\end{array}$ \\
\hline 26 & $X_{\sigma}$ & \begin{tabular}{|l|} 
Outdoor Slow Fading Margin (dB) \\
\end{tabular} & Eq. (14) \\
\hline 27 & $\mathbf{L}_{\mathbf{p}, \text { outdoor }}$ & Maximum Outdoor Path Loss & Eq. (15) \\
\hline \multicolumn{4}{|c|}{ Indoor Coverage Reliability } \\
\hline 28 & $\mathrm{M}_{\text {indoor }}$ & Indoor Penetration Loss $(\mathrm{dB})$ & $20 d B$ \\
\hline 29 & $\sigma_{d B \text {,indoor }}$ & $\begin{array}{llr}\text { Indoor } & \text { Shadowing } & \text { Standard } \\
\text { Deviation }(\mathrm{dB}) & \\
\end{array}$ & $5 \mathrm{~dB}$ \\
\hline 30 & $\sigma_{d B, t o t a l}$ & $\begin{array}{r}\text { Combined Shadowing } \\
\text { Standard Deviation }(\mathrm{dB})\end{array}$ & Eq. (16) \\
\hline 31 & $Y_{\sigma}$ & Indoor Slow Fading Margin (dB) & Eq. (17) \\
\hline 32 & $\mathbf{L}_{\mathrm{p} \text {,indoor }}$ & Maximum Outdoor Path Loss & Eq. (18) \\
\hline
\end{tabular}
of the carrier in $\mathrm{MHz} ; h_{b}$ is the Node B antenna height; $h_{m}$ is the UE antenna height; $d$ is the distance in $\mathrm{km}$ between the UE and Node $\mathrm{B}$; and $L_{c}$ is the clutter correction factor in $\mathrm{dB}$. The correction factor for the UE antenna height is given by

$$
a\left(h_{m}\right)=[1.1 \log f-0.7] \cdot h_{m}-[1.56 \log f-0.8]
$$

TABLE III

Downlink link budget for aWCDMA network.

Tab. IV shows the parameters values used for the cellplanning.

TABLE IV

Parameters used to cell-planning [11].

\begin{tabular}{|c|c|c|c|c|}
\hline Parameter & Value & Parameter & Urban & Dense Urban \\
\hline $\mathbf{f}_{\mathbf{c}}$ & $2.1 \mathrm{GHz}$ & $\mathbf{L}_{\mathbf{c}}$ & $11.0 \mathrm{~dB}$ & $0.0 \mathrm{~dB}$ \\
\hline $\mathbf{h}_{\mathbf{b}}$ & $46 \mathrm{~m}$ & $\boldsymbol{\sigma}_{\boldsymbol{d} \boldsymbol{B}}$ & $8.0 \mathrm{~dB}$ & $7.0 \mathrm{~dB}$ \\
\hline $\mathbf{h}_{\mathbf{m}}$ & $1.5 \mathrm{~m}$ & $\boldsymbol{\sigma}_{d \boldsymbol{d} \text {, } \text {,indoor }}$ & $5.0 \mathrm{~dB}$ & $5.0 \mathrm{~dB}$ \\
\hline
\end{tabular}

The drive tests generally show results of the signal-tointerference-plus-noise ratio (SINR) per chip $E_{c} I_{0}$ in $\mathrm{dB}$ instead of SINR per bit $E_{b} / I_{o}$ in $\mathrm{dB}$. The mapping from $E_{c} / I_{o}$ to $E_{b} / I_{o}$ is given by 


$$
\frac{E_{b}}{I_{0}}=\frac{E_{c}}{I_{0}}+10 \log \left(\frac{W}{R_{b}}\right) .
$$

For AMR speech service, we have $E_{b} / I_{o}=7.0 \mathrm{~dB}$ and $R_{b}=12.2$ kbps. Therefore, the minimum value of $E_{c} / I_{o}=-17.95 \mathrm{~dB}$.

Fig. 8 shows results for a drive test carried out for the macrocell located in an urban clutter (see Fig. 1a). The map of the region uses a scale of 1:200000. Therefore, assuming a SINR per bit of $7.0 \mathrm{~dB}$, we have a coverage radius of approximately $5.0 \mathrm{~km}$.

Fig. 9 shows results for a drive test carried out for the macrocell located in a dense urban clutter (see Fig. 1b). Using the 1:200000 scale, we have a coverage radius of approximately 2.5 $\mathrm{km}$. Notice that in the dense urban cell we have possible holes in the coverage (black points). However, these holes will be covered through a hierarchical cell structured (HCS) when the ARPU increases and the system becomes capacity limited (i.e. interference limited) instead of coverage limited.

Table $\mathrm{V}$ shows the theoretical and measured values for the uplink macrocell range in urban and dense urban clutters. Notice that a urban clutter has a factor correction of $L=11.0 \mathrm{~dB}$, while that a dense urban clutter has a factor correction of $L=0 d B$ (see Tab. IV).

Firstly, it is necessary to observe that the in the used roll-out strategy the system is being designed for outdoor coverage. Therefore, there is an excellent agreement between theoretical and field measured results. Secondly, we have noticed that the indoor penetration loss (see line 24 of Tab. II) is the main responsible for the dramatic decrease in the maximum admissible path loss. Finally, we emphasize that as base of UEs and ARPU increase, then the HCS approach will be deployed to provide indoor coverage and multimedia services.

\section{TABLE V}

Uplink macrocell rage in urban and dense urban clutters.

\begin{tabular}{|c|c|c|c|c|}
\hline \multirow{2}{*}{ UPLINK } & \multicolumn{2}{|c|}{ Urban Clutter } & \multicolumn{2}{c|}{ Dense Urban Clutter } \\
\cline { 2 - 5 } & Outdoor & Indoor & Outdoor & Indoor \\
\hline $\begin{array}{c}\text { Maximum } \\
\text { Path Loss }\end{array}$ & $146.83 \mathrm{~dB}$ & $126.11 \mathrm{~dB}$ & $148.11 \mathrm{~dB}$ & $125.0 \mathrm{~dB}$ \\
\hline $\begin{array}{c}\text { Cell Range } \\
\text { Calculated }\end{array}$ & $4.87 \mathrm{~km}$ & $1.197 \mathrm{~km}$ & $2.52 \mathrm{~km}$ & $0.527 \mathrm{~km}$ \\
\hline $\begin{array}{c}\text { Cell Range } \\
\text { Measured }\end{array}$ & $5.0 \mathrm{~km}$ & - & $2.50 \mathrm{~km}$ & - \\
\hline
\end{tabular}

Tab. VI shows the theoretical values for the downlink macrocell range in urban and dense urban clutters. The designed system is coverage limited. Therefore, the hypothetical coverage range is greater in the downlink since there is availability of power per user in Node B more that it would be necessary to balance the uplink coverage. However, the radio resource management (RRM) algorithms will adjust dynamically the effective power per user, and then there will be a natural balance between uplink and downlink. This extra power will be used when the system becomes capacity limited (i.e. the coverage is now limited by the downlink range).

TABLE VI

Downlink macrocell rage in urban and dense urban clutters.

\begin{tabular}{|c|c|c|c|c|}
\hline \multirow{2}{*}{ DOWNLINK } & \multicolumn{2}{|c|}{ Urban Clutter } & \multicolumn{2}{c|}{ Dense Urban Clutter } \\
\cline { 2 - 5 } & Outdoor & Indoor & Outdoor & Indoor \\
\hline $\begin{array}{c}\text { Maximum } \\
\text { Path Loss }\end{array}$ & $152.15 \mathrm{~dB}$ & $131.43 \mathrm{~dB}$ & $153.43 \mathrm{~dB}$ & $130.32 \mathrm{~dB}$ \\
\hline $\begin{array}{c}\text { Cell Range } \\
\text { Calculated }\end{array}$ & $6.98 \mathrm{~km}$ & $1.71 \mathrm{~km}$ & $3.61 \mathrm{~km}$ & $0.756 \mathrm{~km}$ \\
\hline
\end{tabular}

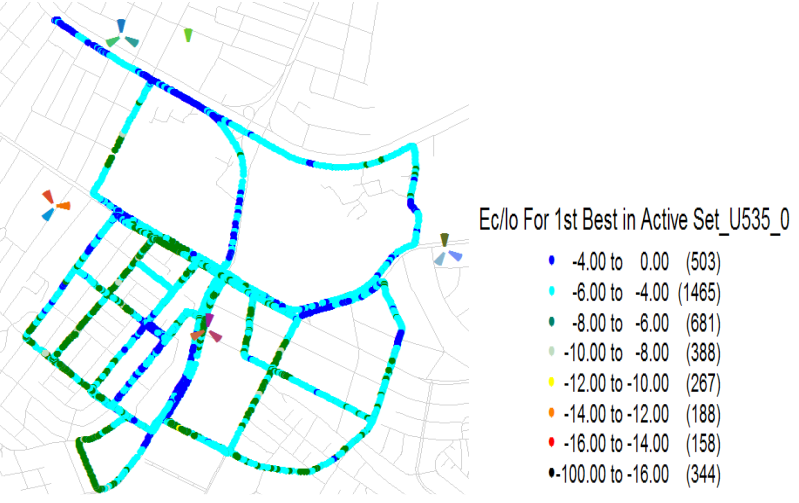

Fig. 8 - Test drive for a macrocell located in an urban clutter.

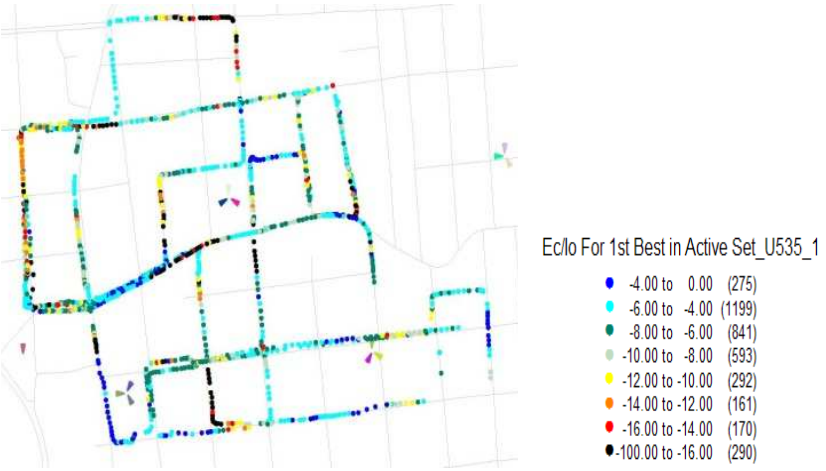

Fig. 9 - Test drive for a macrocell located in a dense urban clutter.

\section{IX - CONCLUDING REMARKS}

We have developed a study of case on the cell-planning process for a practical UTRA WCDMA FDD network in Porto Alegre, Brazil. The used planning process allows unifying smoothly theoretical and practical issues. The methodology used is proved since we have seen an excellent agreement between theoretical and field measured results in spite of greater randomness of system parameters.

\section{REFERENCES}

[1] M. J. Nawrocki, M. Dohler and A. H. Aghvami. Understanding UMTS Radio Network Modeling, Planning and Automated Optimization. John Wiley \& Sons, 2006.

[2] H. Holma and A. Toskala. WCDMA for UMTS: Radio Access for Third Generation Mobile Communications. $3^{\text {th }}$ ed. John Wiley \& Sons, 2004.

[3] R. P. F. Hoefel and C. de Almeida. "The Fading Effects on CDMA/PRMA Performance," Proc. of the Vehicular Technology Conference'99 Spring (VTC'99), Houston, Texas, EUA, May 1999.

[4] L. Kleinrock. Queuing Systems - Vol 1: Theory. John Wiley \& Sons, 1975.

[5] J. S. Lee and L. E. Miller. CDMA Systems Engineering Handbook. Artech House, 1998.

[6] T. Janevski. Traffic Analysis and Design of Wireless IP Networks. Artech House, 2003.

[7] A. Mader,D. Staehle. "Uplink Blocking Probability in Heterogeneous WCDMA Networks considering Other-Cell Interference," http://www3.informatik.uni-wuerzburg.de/TR/tr333.pdf, May 2004

[8] R. Steele, C-C. Lee and P. Gould. GSM, cdmaOne and 3G Systems. John Wiley \& Sons, 2001.

[9] M. da Silva and Y. "Farmine. Uplink Soft Handover Gain Measurements, "Proc. of the Vehicular Technology Conference 2005 Spring (VTC'05 Spring), Stockholm, Texas, Sweden, 2005.

[10] Y-P. Wang and T. Ottoson. "Cell Search in WCDMA," IEEE J. Selected Areas Commun. vol.18, No. 8, 2000, pp. 1470-1482.

[11] Siemens. "Planejamento de Cobertura e Capacidade de Tráfego em Células GSM" in portuguese. 